\title{
Modified FOLFIRI as Second-Line Chemotherapy after Failure of Modified FOLFOX-4 in Advanced Gastric Cancer
}

\author{
Eun Kyoung Jeon, MD' \\ Sook Hee Hong, MD' \\ Tae Hee Kim, MD \\ Seung Eun Jung, MD, PhD² \\ Ji Chan Park, MD' \\ Hye-Sung Won, MD \\ Yoon-Ho Ko, MD' \\ Sang Young Rho, MD' \\ Young Seon Hong, MD, PhD
}

${ }^{\prime}$ Division of Oncology, Department of Internal Medicine, ${ }^{2}$ Department of Radiology, The Catholic University of Korea School of Medicine, Seoul, Korea
Correspondence: Young Seon Hong, MD, PhD Division of Oncology, Department of Internal Medicine, The Catholic University of Korea School of Medicine, 505 Banpo-dong, Seocho-gu, Seoul 137-701, Korea Tel: 82-2-2258-6042

Fax: 82-2-535-1682

E-mail:y331@catholic.ac.kr

Received June 20, 2010

Accepted November 5, 2010

\begin{abstract}
Purpose
The purpose of this study was to evaluate efficacy and toxicity of irinotecan, leucovorin and 5fluorouracil (FOLFIRI) as second-line treatment after failure of oxaliplatin, leucovorin and 5fluorouracil (FOLFOX) for advanced gastric cancer.
\end{abstract}

\section{Materials and Methods}

Patients who received modified FOLFOX-4 as first-line treatment and then received sequential modified FOLFIRI for disease progression were included in this study. The modified FOLFIRI regimen consisted of irinotecan $150 \mathrm{mg} / \mathrm{m}^{2}$ in a 90 -minute intravenous infusion on day 1, leucovorin (LV) $20 \mathrm{mg} / \mathrm{m}^{2}$ and 5-fluorouracil (5-FU) $400 \mathrm{mg} / \mathrm{m}^{2}$ as a bolus followed by $600 \mathrm{mg} / \mathrm{m}^{2}$ as a 22-hour infusion on days 1 and 2 with the same dose of $5-\mathrm{FU} / \mathrm{LV}$ of modified FOLFOX-4 every 2 weeks.

\section{Results}

A total of 32 patients received 126 courses of FOLFIRI chemotherapy. No complete response was achieved. Three patients $(9.4 \%$; $95 \%$ confidence interval [Cl], 0 to $20.1 \%)$ achieved partial response, whereas 11 (34.4\%; 95\% Cl, 17.0 to 51.8\%) patients showed stable disease. Disease control rate (complete response, partial responses and stable diseases) was $43.8 \%$ $(95 \% \mathrm{Cl}, 25.6$ to $61.9 \%$ ) and median follow up duration was 11.3 months (range, 2.23 to 37.9 months). Median time to progression was 2 months ( $95 \% \mathrm{Cl}, 1.49$ to 2.51 months), and median overall survival from the start of FOLFIRI was 5.84 months ( $95 \% \mathrm{Cl}, 4.34$ to 7.34 months). Toxicities were tolerable.

\section{Conclusion}

Modified FOLFIRI as second-line chemotherapy after failure of the modified FOLFOX-4 in advanced gastric cancer was tolerable but showed a lower response rate. Further study about retrying 5-FU/LV with irinotecan after failure of the 5-FU/LV combined regimen is necessary in advanced gastric cancer.

\section{Introduction}

Gastric cancer is the most common cancer in Korea and is the second leading cause of cancer-related deaths [1]. Approximately 20$60 \%$ of patients who have undergone curative surgery for gastric cancer develop recurrent diseases [2], and they undergo palliative chemotherapy.

Palliative chemotherapy has been shown to improve quality of life

\section{Key words}

Stomach neoplasms, Chemotherapy, FOLFIRI 
second-line chemotherapy. However, the efficacy and benefit of second-line chemotherapy for advanced gastric cancer has not been proven, and there is no currently established second-line regimen or treatment options. Nevertheless, most patients want to receive chemotherapy if they are able to.

New agents such as docetaxel and irinotecan are under study as second-line chemotherapy for gastric cancer. Irinotecan is a camptothecan analog that is converted in vivo to $\mathrm{SN}-38$, which binds to the topoisomerase I-DNA complex and thereby disrupts DNA replication and cell division [6]. The mechanism of action of irinotecan is different from that of fluoropyrimidine, platinum and taxane, and irinotecan has no cross-resistance with these agents $[7,8]$. The objective RR of irinotecan is $13 \%$ for gastric cancer patients as a single agent [9]. In combination with 5-FU and leucovorin (LV), the overall RR was 22$42 \%$, and the median OS was 7.6-14.0 months for patients with untreated gastric cancer [10-13]. As second-line chemotherapy, the overall RR of the modified irinotecan, LV and 5-fluorouracil (FOLFIRI) regimen was 10-29\%, with the median time to progression (TTP) being 2.3-4 months and the median OS being 5-10.9 months [14-18].

We treated patients with advanced gastric cancer with the modified oxaliplatin, LV and 5-fluorouracil (FOLFOX) regimen as first-line therapy and then with the modified FOLFIRI regimen as second-line therapy. Our goal in this study was to evaluate the efficacy and toxicity of the modified FOLFIRI regimen following the modified FOLFOX regimen for patients with metastatic gastric cancer.

\section{Materials and Methods}

\section{Patient eligibility}

We retrospectively reviewed all patients with gastric or gastroesophageal junction adenocarcinoma who received the modified FOLFOX-4 regimen as first-line treatment and the modified FOLFIRI regimen as second-line treatment for disease progression between January 2003 and August 2008 at Seoul St. Mary's Hospital. Patients with histologically confirmed and locally advanced, metastatic, or recurrent gastric cancer were eligible. Other eligibility criteria included the age range of 18 to 75 years, an Eastern Clinical Oncology Group (ECOG) performance status of 2 or less, adequate bone marrow and organ functions (an absolute neutrophil count $\geq 1,500 / \mu \mathrm{L}$, platelets $\geq$ $75,000 / \mu \mathrm{L}$, creatinine $<2.0 \mathrm{mg} / \mathrm{dL}$, serum bilirubin $<2.0 \mathrm{mg} / \mathrm{dL}$ and serum transaminase levels $<2$ times the upper normal limit), no past or concurrent history of malignancy other than stomach cancer, except for curatively treated nonmelanoma skin cancer or in situ carcinoma of the cervix uteri. This study was reviewed and approved by Catholic Medical Center Institutional Review Board.

\section{Treatment schedule}

All patients received the modified FOLFOX-4 regimen, and this consisted of intravenous oxaliplatin $100 \mathrm{mg} / \mathrm{m}^{2}$ in a 2-hour intravenous infusion on day $1, \mathrm{LV} 20 \mathrm{mg} / \mathrm{m}^{2}$ and $5-\mathrm{FU} 400 \mathrm{mg} / \mathrm{m}^{2}$ as a bolus followed by $600 \mathrm{mg} / \mathrm{m}^{2}$ as a 22-hour infusion on days 1 and 2, every 2 weeks. As a second-line chemotherapy, the modified FOLFIRI regimen included irinotecan $150 \mathrm{mg} / \mathrm{m}^{2}$ in a 90 -minute intravenous infusion on day 1 , LV $20 \mathrm{mg} / \mathrm{m}^{2}$ and 5-FU $400 \mathrm{mg} / \mathrm{m}^{2}$ as a bolus followed by $600 \mathrm{mg} / \mathrm{m}^{2}$ as a 22-hour infusion on days 1 and 2, every 2 weeks. Atropine was not routinely used. All patients received adequate anti-emetic therapy prior to chemotherapy. Loperamide was prescribed prophylactically and the patients were instructed to take loperamide in case of developing diarrhea. Treatment was continued until documented disease progression, unacceptable toxicity or patient refusal.

\section{$3 \overline{\text { Dose modifications }}$}

Chemotherapy was delayed if the patient $\mathrm{s}$ granulocyte count was $<1,500 / \mathrm{mm}^{3}$ or the platelet count did not return to a minimum of $75,000 / \mathrm{mm}^{3}$ on the day of infusion. Other toxicities (except alopecia) were required to be either grade 0 or 1 before another cycle was started. The 5-FU dosage was reduced by $20 \%$ in the next cycle if a related grade 3 or worse toxicity (mucositis and hand-foot syndrome) occurred. The dose of irinotecan was not reduced by the occurrence of mucositis or hand-foot syndrome. The dose of irinotecan and 5-FU were reduced by $20 \%$ for grade 4 neutropenia lasting 7 days or more, neutropenic fever, grade 4 thrombocytopenia, grade 3 thrombocytopenia with bleeding requiring platelet transfusion, and grade $3 / 4$ non-hematologic toxicities other than nausea and vomiting.

\section{Assessment of efficacy and toxicity}

Physical examination, chest X-rays, complete blood counts and biochemical tests were performed before each chemotherapy cycle. Computed tomography (CT) scans were performed every three cycles or when disease progression was suspected. The tumor response was classified according to the Response Evaluation Criteria in Solid Tumors (RECIST) criteria. If there was no measurable lesion, the evaluable lesion was assessed. The presence or absence of each lesion was noted throughout follow-up. The CT scans were reviewed by a single experienced radiologist (SEJ). The toxicity was evaluated according to the National Cancer Institute-Common Toxicity Criteria (NCI-CTC, ver. 3.0) at each cycle.

\section{Statistics}

Descriptive statistics were reported as proportions and medians. The TTP was measured from the first day of FOLFIRI treatment until the date of disease progression, the date of the last follow-up, or the date of 
the decision to receive palliative care when no further imaging study had been performed. The OS was measured from the first day of FOLFIRI chemotherapy until death or the date of the last follow up. The TTP and OS were estimated by the Kaplan-Meier method. All the statistical analyses were performed using SPSS ver. 13.0 (SPSS Inc., Chicago, IL).

\section{Results}

\section{$1 \longdiv { \text { Patient characteristics } }$}

A total of 104 patients received modified FOLFOX-4 as first line chemotherapy for advanced or recurrent gastric cancer between January 2003 and August 2008 at Seoul St. Mary s Hospital. A total of 37 patients received modified FOLFIRI as second-line chemotherapy and 32 of these patients were eligible.

Patient characteristics are summarized in Table 1. The median age of the patients was 59 years (range, 33 to 72 years). The male to female ratio was $22: 10$. Thirteen $(40.6 \%)$ of the patients had an ECOG performance status of 2 . Thirty $(93.8 \%)$ patients had metastatic disease and only $2(6.2 \%)$ patients had locally advanced disease. Four patients $(12.5 \%)$ had gastroesopheal junction adenocarcinoma. Ten (31.25\%) patients had metastases in more than 3 organs, and the most common metastatic organ was peritoneum. The median hemoglobin level was $10.8 \mathrm{~g} / \mathrm{dL}$ (range, 7.5 to $14.2 \mathrm{~g} / \mathrm{dL}$ ).

\section{Treatment administration and toxicity}

Patients received a total of 126 cycles of FOLFIRI chemotherapy, with a median of three cycles (range, 1 to 10 cycles) per patient. Dose reduction was applied in 29 cycles $(23.0 \%)$ and the chemotherapy schedule was delayed in 20 cycles $(15.9 \%)$, primarily due to hematological toxicity. The toxicities are listed in Table 2. No deaths due to toxicity occurred and the toxicities were tolerable. The most common toxicity was anemia in $27(84.4 \%)$ patients. Grade 3 or 4 anemia occurred in $2(6.2 \%)$ patients. Grade 3 or 4 neutropenia was observed in $7(21.9 \%)$ patients. The non-hematologic toxicities consisted primarily of nausea and vomiting. Grade 1 or 2 diarrhea occurred in 2 (6.2\%) patients.

\section{Efficacy and survival}

With the intent-to-treat analysis, the overall RR was 9.4\% (Table 3). No patient had a complete response (CR), whereas $3(9.4 \% ; 95 \%$ confidence interval [CI], 0 to 20.1\%) patients achieved partial responses (PR), and stable diseases (SD) were documented in 11 (34.4\%; 95\% CI, 17.0 to $51.8 \%$ ) patients. The disease control rate (CR, PR and SD) was 43.8\% (95\% CI, 25.6 to $61.9 \%)$. Ten (31.2\%; 95\%
Table 1. Patient characteristics

\begin{tabular}{|c|c|}
\hline Characteristics & No. of patients $(\%)$ \\
\hline \multicolumn{2}{|l|}{ Gender } \\
\hline Male & $22(68.75)$ \\
\hline Female & $10(31.25)$ \\
\hline Median age (range, yr) & $59(33-72)$ \\
\hline \multicolumn{2}{|l|}{ ECOG performance status } \\
\hline 0 & $8(25)$ \\
\hline 1 & $11(34.4)$ \\
\hline 2 & $13(40.6)$ \\
\hline \multicolumn{2}{|l|}{ Extent of disease } \\
\hline Metastatic & $27(84.4)$ \\
\hline Recurrent & $3(9.4)$ \\
\hline Locally advanced & $2(6.2)$ \\
\hline \multicolumn{2}{|l|}{ Operation } \\
\hline Curative & $3(9.4)$ \\
\hline Palliative & $2(6.2)$ \\
\hline \multicolumn{2}{|l|}{ Primary site } \\
\hline Unkown & $1(3.1)$ \\
\hline Gastroesopheal junction & $4(12.5)$ \\
\hline Body & $27(84.4)$ \\
\hline \multicolumn{2}{|l|}{ Metastatic number } \\
\hline 0 & $1(3.1)$ \\
\hline 1 & $6(18.8)$ \\
\hline 2 & $15(46.9)$ \\
\hline$\geq 3$ & $10(31.2)$ \\
\hline \multicolumn{2}{|l|}{ Metastatic lesion } \\
\hline Liver & $6(18.8)$ \\
\hline Peritoneum & $21(65.6)$ \\
\hline Bone & $7(21.9)$ \\
\hline \multicolumn{2}{|l|}{ Measurable lesion } \\
\hline No measurable & $10(31.25)$ \\
\hline Measurable & $22(68.75)$ \\
\hline \multicolumn{2}{|l|}{ Differentiation } \\
\hline Well & $0(0)$ \\
\hline Moderate & $9(28.1)$ \\
\hline Poor & $19(59.4)$ \\
\hline Unknown & $4(12.5)$ \\
\hline \multicolumn{2}{|c|}{ Median complete blood count (range) } \\
\hline Hemoglobin (g/dL) & $10.8(7.5-14.2)$ \\
\hline White blood cell $\left(\times 10^{9} / \mathrm{L}\right)$ & $5,450(2,980-16,990)$ \\
\hline Plate count $\left(\times 10^{9} / \mathrm{L}\right)$ & $197(81-462)$ \\
\hline
\end{tabular}

ECOG, Eastern Clinical Oncology Group.

CI, 14.3 to $48.2 \%$ ) patients had progressive diseases (PD). The tumor responses were not evaluated in 8 (25\%) patients; 6 patients showed clinical progression with aggravation of their performance status, while 2 patients were lost to follow-up. Nineteen (59.4\%) patients received third line chemotherapy after failure of FOLFIRI regimen.

The median follow up duration was 11.3 months (range, 2.23 to 37.9 months). The median TTP for the FOLFIRI regimen was 2 months (95\% CI, 1.49 to 2.51 months) (Fig. 1). The median OS was 5.84 
Table 2. Toxicity profiles of FOLFIRI (per patient)

\begin{tabular}{|c|c|c|c|c|c|}
\hline & \multicolumn{5}{|c|}{ NCI-CTCAE grade $(\%)$} \\
\hline & G1 & G2 & G3 & G4 & All \\
\hline \multicolumn{6}{|c|}{ Non hematologic toxicities } \\
\hline Nausea & $5(15.6)$ & $6(18.8)$ & $3(9.4)$ & 0 & $14(43.8)$ \\
\hline Vomiting & $3(9.4)$ & $6(18.8)$ & $2(6.2)$ & 0 & $11(34.4)$ \\
\hline Diarrhea & $1(3.1)$ & $1(3.1)$ & 0 & 0 & $2(6.2)$ \\
\hline Hepatoxicity & $6(18.8)$ & 0 & 0 & $1(3.1)$ & $7(21.9)$ \\
\hline \multicolumn{6}{|l|}{ Hematologic toxicities } \\
\hline Neutropenia & $5(15.6)$ & $7(21.9)$ & 0 & $7(21.9)$ & $19(59.4)$ \\
\hline Anemia & $11(34.4)$ & $13(40.6)$ & $1(3.1)$ & $2(6.2)$ & $27(84.4)$ \\
\hline Thrombocytopenia & $3(9.4)$ & $2(6.2)$ & $1(3.1)$ & 0 & $6(18.8)$ \\
\hline Febrile neutropenia & 0 & 0 & 0 & 0 & 0 \\
\hline
\end{tabular}

FOLFIRI, irinotecan, leucovorin and 5-fluorouracil; NCI-CTCAE ver. 3.0, National Cancer Institute-Common Toxicity Criteria for Adverse Events ver. 3.0.

Table 3. Efficacy of FOLFIRI

\begin{tabular}{lcc}
\multicolumn{1}{c}{ Response } & No. of patients $(\%)$ & $95 \%$ confidence interval \\
\hline Complete response & $0(0)$ & - \\
Partial response & $3(9.4)$ & $0-20.1$ \\
Stable disease & $11(34.4)$ & $17.0-51.8$ \\
Progressive disease & $10(31.2)$ & $14.3-48.2$ \\
Not assessable & $8(25)$ & - \\
\hline
\end{tabular}

FOLFIRI, irinotecan, leucovorin and 5-fluorouracil.

months (95\% CI, 4.34 to 7.34 months) (Fig. 2).

\section{Discussion}

This study assessed the efficacy and toxicity of the FOLFIRI regimen as second-line treatment after failure of the modified FOLFOX-4 regimen. The treatment was well-tolerated. The most predominant grade 3 or 4 toxicity was neutropenia. Febrile neutropenia was not seen. There was no grade 3 or 4 diarrhea, and only 3 patients (8.1\%) had grade 1 or 2 diarrhea. This low rate of diarrhea, as compared with that of other irinotecan based studies, could be explained by the low dose of irinotecan and the ethnic differences of uridine diphosphate glucuronosyltransferase 1 (UGT1A1). Irinotecan is biotransformed into its active metabolite SN-38, and SN-38 is inactivated by UGT1A1 through glucuronidation. Depending on the number of TA insertions in the TATAA element of the 5 ' promoter region, the genotype of the UGT1A1*28 allele is named as the wild-type (6/6), the heterozygous genotype (6/7) and the homozygous genotype (7/7). The patients carrying the heterozygous or homozygous genotype experienced a decreased expression of the UGT1A1 enzyme, resulting in a lower rate of SN-38 glucuronidation. The association between the UGT1A1 gene polymorphism and increased toxicity in patients who received irinotecan-based chemotherapy is well known [6]. Liu et al.
[19] showed the predominance of the UGT1A1 (6/6) genotype in Asians (76\%) compared with 46\% in Caucasians [19]. A high rate of grade 3 or 4 toxic diarrhea $(48.9 \%)$ was reported at $180 \mathrm{mg} / \mathrm{m}^{2}$ irinotecan in French patients [11], but this was $10 \%$ at $125 \mathrm{mg} / \mathrm{m}^{2}$ in American patients [10], and $6 \%$ at $180 \mathrm{mg} / \mathrm{m}^{2}$ in Korean patients [15].

There is no standard first-line treatment for advanced gastric cancer, yet a 5-FU and platinum based regimen is usually administered and a modified FOLFOX-4 regimen is one of the commonly used regimens. Several phase II studies have reported the efficacy of the modified FOLFIRI regimen as a second-line or salvage regimen after failure of a 5-FU combined regimen (Table 4), for which the response rate was 1029\%. The TTP was 2.3-4 months and the OS was 5-10.9 months. Our study showed a lower overall RR but had similar disease control rate (CR, PR and SD) and similar OS with the other studies. This study included 10 (31.3\%) patients without measurable lesions. These patients only had evaluable lesions and were evaluated for only SD or PD responses, resulting in a low $R R$.

Based on the results of the phase III study [20], we used a low dose of LV. Jäger et al. [20] compared the therapeutic effects and toxicity of high-dose LV/5-FU versus low-dose LV/5-FU for treating colon cancer. The high dose LV/5-FU was not superior to the low-dose LV/5-FU, yet the RR and OS were comparable, but the treatmentrelated toxicity was higher in the high dose LV/5-FU group.

A low dose of irinotecan and the same dose of the prior failed regimen (5-FU/LV) with same infusion-method could also be reasons for the low RR and shorter TTP. Also, a synergistic effect of irinotecan and 5-FU/LV is controversial. In some studies, combining irinotecan with 5-FU/LV showed synergistic effects after failure of 5-FU/LV [2123]. However, the FOLFIRI regimen as the second-line therapy had a lower response rate than the RR of second-line FOLFOX with the same dose of 5-FU/LV in advanced colon cancer [24]. In addition, the efficacy of irinotecan alone was comparable to that of 5-FU/LV and irinotecan after failure of 5-FU/LV [25]. Therefore, after failure of FOLFOX, irinotecan single chemotherapy, combination of irinotecan with other doses of 5-FU/LV can be considered. 


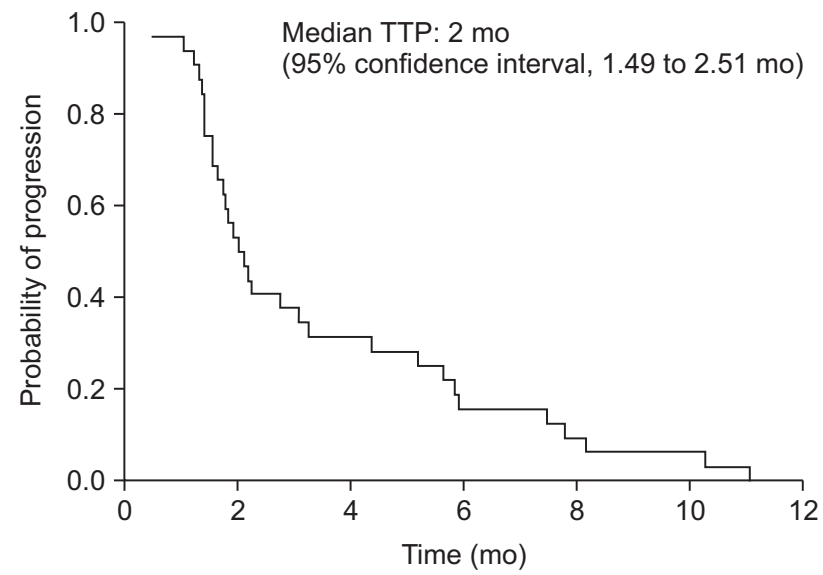

Fig. 1. Time to progression (TTP) curve.

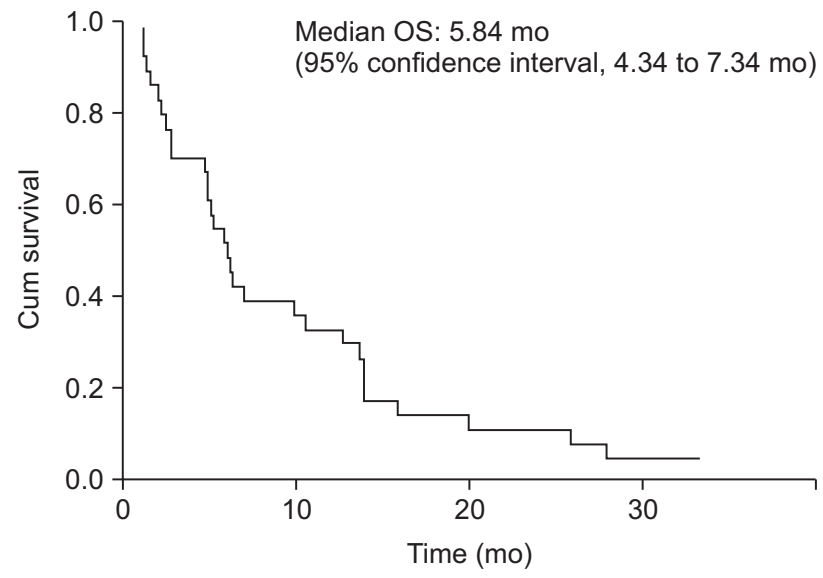

Fig. 2. Overall survival (OS) curve.

Table 4. Phase II studies on irinotecan, 5-FU, and LV combination chemotherapy for advanced gastric cancer

\begin{tabular}{|c|c|c|c|c|c|c|c|}
\hline & $\begin{array}{c}\text { Previous } \\
\text { chemotherapy }\end{array}$ & $\begin{array}{c}\text { No. of } \\
\text { previous } \\
\text { chemo-regimen }\end{array}$ & Regimen & $\mathrm{RR}(\%)$ & $\mathrm{SD}(\%)$ & TTP (mo) & OS (mo) \\
\hline Lorizzo et al. [16] & $\begin{array}{l}\text { Not restricted, } \\
\text { fluoropyrimidine based, } \\
\text { regimen }(71.43 \%) \text { included, } \\
\text { no FOLFOX }\end{array}$ & 1 & $\begin{array}{l}\text { I } 180 \mathrm{mg} / \mathrm{m}^{2} \mathrm{D} 1 \\
\text { LV } 200 \mathrm{mg} / \mathrm{m}^{2} \text { bolus D1 } \\
\text { 5-FU } 400 \mathrm{mg} / \mathrm{m}^{2} \text { bolus, } \\
\text { 2,400 } \mathrm{mg} / \mathrm{m}^{2} \text { over } 46 \mathrm{hr}\end{array}$ & 21 & 21 & 4 & 5 \\
\hline Assersohn et al. [15] & $\begin{array}{l}\text { Not restricted, } \\
\text { fluoropyrimidine based, } \\
\text { regimen }(97.4 \%) \text { included, } \\
\text { no FOLFOX }\end{array}$ & 1 & $\begin{array}{l}\text { I } 180 \mathrm{mg} / \mathrm{m}^{2} \mathrm{D} 1 \\
\text { LV } 125 \mathrm{mg} / \mathrm{m}^{2} \text { bolus D1 } \\
\text { 5-FU } 400 \mathrm{mg} / \mathrm{m}^{2} \text { bolus, } \\
1,200 \mathrm{mg} / \mathrm{m}^{2} \text { over } 48 \mathrm{hr}\end{array}$ & 29 & 34 & 3.7 & 6.4 \\
\hline Seo et al. [14] & $\begin{array}{l}\text { Not restricted, } \\
\text { fluoropyrimidine based, } \\
\text { regimen }(75 \%) \text { included, } \\
\text { modified FOLFOX } \\
(29 \%) \text { included }\end{array}$ & 1 & $\begin{array}{l}\text { I } 180 \mathrm{mg} / \mathrm{m}^{2} \mathrm{D} 1 \\
\text { LV } 200 \mathrm{mg} / \mathrm{m}^{2} \text { bolus D1, } 2 \\
5 \text {-FU } 400 \mathrm{mg} / \mathrm{m}^{2} \text { bolus, } \\
600 \mathrm{mg} / \mathrm{m}^{2} \text { over } 22 \mathrm{hr} \mathrm{D} 1,2\end{array}$ & 18 & 29 & 3.2 & 9.1 \\
\hline Kim et al. [18] & Fluoropyrimidine based regimen & $\geq 1$ & $\begin{array}{l}\text { I } 150 \mathrm{mg} / \mathrm{m}^{2} \mathrm{D} 1 \\
\mathrm{LV} 20 \mathrm{mg} / \mathrm{m}^{2} \text { bolus D1, } 2 \\
5 \text {-FU } 3,000 \mathrm{mg} / \mathrm{m}^{2} \text { over } 48 \mathrm{hr}\end{array}$ & 18.2 & 18.2 & 2.3 & 5.1 \\
\hline Kim et al. [17] & $\begin{array}{l}\text { Not restricted, } \\
\text { modified FOLFOX } \\
(52.6 \%) \text { included }\end{array}$ & $\geq 1$ & $\begin{array}{l}\text { I } 150 \mathrm{mg} / \mathrm{m}^{2} \mathrm{D} 1 \\
\mathrm{LV} 20 \mathrm{mg} / \mathrm{m}^{2} \text { bolus D1, } 2 \\
5 \text {-FU } 400 \mathrm{mg} / \mathrm{m}^{2} \text { bolus, } \\
600 \mathrm{mg} / \mathrm{m}^{2} \text { over } 22 \mathrm{hr} \mathrm{D} 1,2\end{array}$ & 10 & 36.7 & 3.3 & 10.9 \\
\hline This study & Modified FOLFOX & 1 & $\begin{array}{l}\text { I } 150 \mathrm{mg} / \mathrm{m}^{2} \mathrm{D} 1 \\
\text { LV } 20 \mathrm{mg} / \mathrm{m}^{2} \text { bolus D1, } 2 \\
\text { 5-FU } 400 \mathrm{mg} / \mathrm{m}^{2} \text { bolus, } \\
600 \mathrm{mg} / \mathrm{m}^{2} \text { over } 22 \mathrm{hr} \mathrm{D1,2}\end{array}$ & 9.1 & 34.4 & 2 & 5.84 \\
\hline
\end{tabular}

5-FU, 5-fluorouracil; LV, leucovorin; RR, response rate; SD, stable diseases; TTP, time to progression; OS, overall survival; I, irinotecan; D, day.

\section{Conclusion}

The modified FOLFIRI regimen as second-line therapy after failure of the modified FOLFOX-4 regimen in patients with advanced gastric cancer was tolerable, but our study showed a lower response rate than that of other studies on second-line FOLFIRI after failure with various first-line chemotherapy strategies. Re-administration of failed 5FU/LV with the same dose and with the same infusion method in the modified FOLFIRI regimen could be one of the reasons for this. 
Further study on retrying 5-FU/LV with irinotecan after failure of the 5-FU/LV combined regimen in advanced gastric cancer patients is necessary.

\section{Conflicts of Interest}

Conflict of interest relevant to this article was not reported.

\section{References}

1. Yaich L, Dupont WD, Cavener DR, Parl FF. Analysis of the Pvull restriction fragmentlength polymorphism and exon structure of the estrogen receptor gene in breast cancer and peripheral blood. Cancer Res. 1992;52:77-83.

2. Yoo CH, Noh SH, Shin DW, Choi SH, Min JS. Recurrence following curative resection for gastric carcinoma. Br J Surg. 2000;87:236-42.

3. Glimelius B, Ekström K, Hoffman K, Graf W, Sjödén PO, Haglund U, et al. Randomized comparison between chemotherapy plus best supportive care with best supportive care in advanced gastric cancer. Ann Oncol. 1997;8:163-8.

4. Vanhoefer U, Rougier P, Wilke H, Ducreux MP, Lacave AJ, Van Cutsem E, et al. Final results of a randomized phase III trial of sequential high-dose methotrexate, fluorouracil, and doxorubicin versus etoposide, leucovorin, and fluorouracil versus infusional fluorouracil and cisplatin in advanced gastric cancer: a trial of the European Organization for Research and Treatment of Cancer Gastrointestinal Tract Cancer Cooperative Group. J Clin Oncol. 2000;18:2648-57.

5. Ross P, Nicolson M, Cunningham D, Valle J, Seymour M, Harper P, et al. Prospective randomized trial comparing mitomycin, cisplatin, and protracted venous-infusion fluorouracil (PVI 5-FU) with epirubicin, cisplatin, and PVI 5-FU in advanced esophagogastric cancer. J Clin Oncol. 2002;20:1996-2004.

6. Schulz C, Boeck S, Heinemann V, Stemmler HJ. UGT1A1 genotyping: a predictor of irinotecan-associated side effects and drug efficacy? Anticancer Drugs. 2009;20:86779

7. Saltz LB, Cox JV, Blanke C, Rosen LS, Fehrenbacher L, Moore MJ, et al. Irinotecan plus fluorouracil and leucovorin for metastatic colorectal cancer. Irinotecan Study Group. N Engl J Med. 2000;343:905-14.

8. Douillard JY, Cunningham D, Roth AD, Navarro M, James RD, Karasek P, et al. Irinotecan combined with fluorouracil compared with fluorouracil alone as first-line treatment for metastatic colorectal cancer: a multicentre randomised trial. Lancet. 2000:355:1041-7.

9. Kohne CH, Thuss-Patience P, Catane R, Klein H, Peretz T, Preusser P, et al. Final results of a phase II trial of CPT-11 in patients with advanced gastric cancer. Proc Am Soc Clin Oncol. 1999;18:Abstr 993

10. Bouché O, Raoul JL, Bonnetain F, Giovannini M, Etienne PL, Lledo G, et al. Randomized multicenter phase II trial of a biweekly regimen of fluorouracil and eucovorin (LV5FU2), LV5FU2 plus cisplatin, or LV5FU2 plus irinotecan in patients with previously untreated metastatic gastric cancer: a Federation Francophone de Cancerologie Digestive Group Study--FFCD 9803. J Clin Oncol. 2004;22:4319-28.

11. Yilmaz U, Oztop I, Alacacioglu A, Yaren A, Tarhan O, Somali I. Irinotecan combined with infusional 5-fluorouracil and high-dose leucovorin for the treatment of advanced gastric carcinoma as the first-line chemotherapy. Chemotherapy. 2006;52:264-70.

12. Rosati G, Cordio S, Caputo G, Condorelli S, Germano D, Mattina M, et al. Phase II trial of a biweekly regimen of fluorouracil and leucovorin plus irinotecan in patients with previously untreated advanced gastric cancer. J Chemother. 2007;19:570-6.

13. Park SH, Nam E, Park J, Cho EK, Shin DB, Lee JH, et al. Randomized phase II study of irinotecan, leucovorin and 5-fluorouracil (ILF) versus cisplatin plus ILF (PILF) combination chemotherapy for advanced gastric cancer. Ann Oncol. 2008;19:729-33.

14. Seo MD, Lee KW, Lim JH, Yi HG, Kim DY, Oh DY, et al. Irinotecan combined with 5fluorouracil and leucovorin as second-line chemotherapy for metastatic or relapsed gastric cancer. Jpn J Clin Oncol. 2008;38:589-95.

15. Assersohn L, Brown G, Cunningham D, Ward C, Oates J, Waters JS, et al. Phase II study of irinotecan and 5 -fluorouracil/leucovorin in patients with primary refractory or relapsed advanced oesophageal and gastric carcinoma. Ann Oncol. 2004;15:64-9.

16. Lorizzo K, Fazio N, Radice D, Boselli S, Ariu L, Zampino MG, et al. Simplified FOLFIRI in pre-treated patients with metastatic gastric cancer. Cancer Chemother Pharmacol. 2009;64:301-6.

17. Kim SG, Oh SY, Kwon HC, Lee S, Kim JH, Kim SH, et al. A phase II study of irinotecan with bi-weekly, low-dose leucovorin and bolus and continuous infusion 5-fluorouracil (modified FOLFIRI) as salvage therapy for patients with advanced or metastatic gastric cancer. Jpn J Clin Oncol. 2007:37:744-9.

18. Kim SH, Lee GW, Go SI, Cho SH, Kim HJ, Kim HG, et al. A phase II study of irinotecan, continuous 5-fluorouracil, and leucovorin (FOLFIRI) combination chemotherapy for patients with recurrent or metastatic gastric cancer previously treated with a fluoropyrimidine-based regimen. Am J Clin Oncol. 2010;33:572-6.

19. Liu JY, Ou K, Sferruzza AD, Bender RA. Distribution of the UGT1A1*28 polymorphism in Caucasian and Asian populations in the US: a genomic analysis of 138 healthy individuals. Anticancer Drugs. 2007;18:693-6.

20. Jäger E, Heike M, Bernhard H, Klein O, Bernhard G, Lautz D, et al. Weekly high-dose leucovorin versus low-dose leucovorin combined with fluorouracil in advanced colorectal cancer: results of a randomized multicenter trial. Study Group for Palliative Treatment of Metastatic Colorectal Cancer Study Protocol 1. J Clin Oncol. 1996;14:2274-9.

21. Rothenberg ML, Oza AM, Bigelow RH, Berlin JD, Marshall JL, Ramanathan RK, et al. Superiority of oxaliplatin and fluorouracil-leucovorin compared with either therapy alone in patients with progressive colorectal cancer after irinotecan and fluorouracilleucovorin: interim results of a phase III trial. J Clin Oncol. 2003;21:2059-69.

22. de Gramont A, Vignoud J, Tournigand C, Louvet C, André T, Varette C, et al. Oxaliplatin with high-dose leucovorin and 5 -fluorouracil 48-hour continuous infusion in pretreated metastatic colorectal cancer. Eur J Cancer. 1997;33:214-9.

23. Mans DR, Grivicich I, Peters GJ, Schwartsmann G. Sequence-dependent growth inhibition and DNA damage formation by the irinotecan-5-fluorouracil combination in human colon carcinoma cell lines. Eur J Cancer. 1999;35:1851-61.

24. Tournigand C, André T, Achille E, Lledo G, Flesh M, Mery-Mignard D, et al. FoLFIRI followed by FOLFOX6 or the reverse sequence in advanced colorectal cancer: a randomized GERCOR study. J Clin Oncol. 2004;22:229-37.

25. Seymour MT, Maughan TS, Ledermann JA, Topham C, James R, Gwyther SJ, et al. Different strategies of sequential and combination chemotherapy for patients with poor prognosis advanced colorectal cancer (MRC FOCUS): a randomised controlled trial. Lancet. 2007;370:143-52. 